\title{
Healthy Cities South Auckland: A focus on youth leadership and sustainability in the post-COVID world
}

Cath Conn ${ }^{1}$, Robert Field ${ }^{2}$, Margaret Hinepo Williams ${ }^{1}$, Radilaite Cammock ${ }^{1}$, and Adetoun Nnabugwu ${ }^{1}$

1 Auckland University of Technology Child and Youth Health Research Centre, New Zealand

2 Dornsife School of Public Health at Drexel University, Philadelphia, US

\section{Abstract}

Introduction: This paper draws on a presentation given at the American Public Health Association (APHA) annual meeting in Philadelphia in 2019 (Drs. Conn and Field). It is based on an innovative public health initiative in the Aotearoa New Zealand context, which incorporates key themes relating to sustainable and healthy cities in the post-COVID world.

Method: Healthy cities South Auckland began in 2019, and involves Auckland University of Technology (AUT) faculty and students, many of whom are from indigenous Māori and Pacific Island communities, working collaboratively. The initiative aims to improve the health and wellbeing of the urban population using a series of codesigned projects that prioritise youth leadership and principles of sustainability. Current projects include an investigation of healthy food youth enterprise and the role of urban sustainable food environments; and student, faculty, and industry codesign of future-oriented public health higher education.

Discussion: Whilst this public health initiative is grounded in known principles of community action and determinants of health, it is innovative in the close and contextualised attention to Māori and Pacific youth leadership and to a more overt sustainability agenda. Emphasising the shift from healthy cities focusing on people, to one that focuses on the inextricable link between people and the natural environment, the initiative is underpinned by indigenous guardianship concepts, such as Māori Kaitiakitanga (guardianship of the natural order) and Pacific Va (healthy spaces). Traditionally associated with rural and marine spaces, a valuable new development is the application of indigenous principles by youth in an urban setting and for a public health agenda. These notions resonate with global shifts such as the 'school strikes for climate change' movement and seem particularly apt in a post-COVID world which must mobilise new ways of bringing about transformative change. These include addressing disease 
outbreaksand chronic disease and health inequities, while also taking into consideration the contexts of community, culture and natural environments.

Conclusion: In the Aotearoa New Zealand context, strengths-based approaches are a vital way forward, positioning Māori and Pacific young people as champions. Notions of healthy cities as sustainable cities; based on indigenous guardianship applied to $21^{\text {st }}$ century urban spaces; youth activism and urban health in the digital age; and partnership between academia, youth, and industry are significant areas for further study, providing useful lessons for cities' agendas, both locally and internationally.

Keywords: Healthy cities; sustainable cities; youth leadership; South Auckland; indigenous guardianship; Māori and Pacific youth; Kaitiakitanga

The authors are a group of researchers contributing to the field of public health, actively collaborating to lead innovative and indigenous research. All authors, except one, are affiliated with the Child and Youth Health Research Centre at Auckland University of Technology, New Zealand https://cyhrc.aut.ac.nz . Professor Robert Field holds a joint appointment as professor of law at the Kline School of Law and professor of health management and policy at the Dornsife School of Public Health at Drexel University, Philadelphia, US. Professor Field was funded through the Fulbright Specialist Program in 2018 to visit Auckland University of Technology where he conceptualized this project. The corresponding author is Cath Conn (cath.conn@aut.ac.nz). 


\section{Introduction}

\section{The urban environment of South Auckland}

Cities around the world are already planning for life after COVID-19, with a series of environmental initiatives being rolled out from Bogotá to Barcelona to ensure public safety and bolster the fight against climate breakdown. (Taylor \& Laville, 2020)

In the wake of the COVID crisis, mayors around the world are seizing the opportunity to make transformative change to the urban landscape with a view to heralding new kinds of cities - those which are healthier for people and planet. (C40 Cities, 2020)

As a fast-growing and dynamic urban area, Auckland is facing similar challenges to cities around the world. The Auckland region, with slightly fewer than 1.6 million people, a third of the country's population (Stats NZ, 2020a), is situated on the North Island of Aotearoa New Zealand. The City and wider conurbation are growing quickly, with an estimated population of around 2 million by 2040. These trajectories are based on a combination of inward skilled migration and high fertility amongst indigenous Māori and Pacific Island communities (Stats NZ, 2020a, 2020b). As Aotearoa New Zealand's largest and most diverse city, Auckland is the major economic and financial centre, with strengths in finance, commerce, and tourism (New Zealand Now, 2020). The median household gross income was $94,465^{1}$ NZD $(60,596$ USD) in 2019, which is higher than the median household gross income of all regions $(80,354$ NZD) and about three times more than the national median personal income (33,280 NZD) (Stats NZ, 2020c). In the wake of the negative effect of COVID-19 on the economy, the coalition government under Prime Minister Jacinda Ardern (re-elected in October 2020), is committed to bringing forward stimulus projects such as transport and housing infrastructure, skills and apprenticeship programmes (NZ Labour Party, 2020), and other projects aimed at improving the natural environment.

Auckland has a diverse population in terms of ethnicity, and it is the largest Polynesian city in the world (New Zealand Now, 2020; World Population Review, 2020). As the most culturally and ethnically diverse region, census data for Auckland show that people of European origin comprise 53.5\% of

${ }^{1}$ Income rounded to the nearest dollar. USD conversion rate used was $1 \mathrm{NZD}=0.641471$ USD from here on 2020-06-28 23:20 UTC 
the population; Asian communities make up 28.2\%; those from the Pacific Islands 15.5\%; Māori communities 11.5\%; while Middle-Eastern, Latin American, and African (MELAA) groups are 2.3\%; and others $1.1 \%$ (Stats NZ, 2020d, 2020e).

Although 'South Auckland' is not an official place name it has come into common use to delineate the southern section of the conurbation, with a population of approximately half a million (Ministry of Health NZ, 2019a). Among the distinctive features of the South Auckland population are youthfulness, dynamism, and a rich diversity of cultures - especially those of Māori, Pacific, and South Asian communities. It has a high proportion of low socio-economic communities; and high levels of ill-health exacerbated by poor quality housing, unhealthy food environments and related diets, poverty and institutional racism, low educational attainment, and lack of activity and sedentarism (Ministry of Health NZ, 2019b).

The population in South Auckland is more youthful than the national average, with $59.2 \%$ aged 39 years or younger compared to $53.6 \%$ in the nation as a whole (Auckland Council, 2018; Stats NZ, 2020e). It also has a high fertility rate compared to other regions of the country. South Auckland is most easily defined by the area served by the Counties Manukau district health board (one of three Auckland area health administrative entities). District health boards are responsible for funding and provision of health services in their designated area. Research shows that Pacific island communities, predominantly migrants from Samoa, Tonga, and Fiji, are more likely to be in the most socio-economically deprived quintile compared to other ethnic groups (Ministry of Health NZ, 2019b).

Auckland Council, the governing body for the city, has a strong commitment to health and sustainability (Auckland Council, 2020). With the Auckland Plan 2050, it has a directional guide that informs its funding initiatives and work programmes to improve the quality of life and standards of living of its resident population. However, despite having policy statements in place, Auckland, and Aotearoa New Zealand as a whole, have underfunded public health programmes - including those with an emphasis on environment reflected in the lack of attention to health disparities and determinants of health (Auckland Council, 2018, 2020; Hobbs et al., 2019; Ministry of Health, 2019a; Sheridan et al., 2011).

\section{Background of the initiative}

The underlying concept for the initiative is based on the World Health Organization's (WHO) 'Healthy Cities' concept, which promotes community 
participation and empowerment, intersectoral partnerships, and participant equity in cities and communities globally (WHO, 1998). The WHO (1998) defined a 'healthy city' as 'one that is continually creating and improving those physical and social environments and expanding those community resources which enable people to mutually support each other in performing all the functions of life and developing to their maximum potential' (p. 13).

In 2010, Auckland University of Technology (AUT) opened the first university campus in the heart of South Auckland. Since then, student numbers have grown significantly with high proportions of Māori and Pacific students (AUT, 2020). Healthy Cities South Auckland, based at this campus, focuses on the loosely-defined community of around half a million people described above, with the integrated aim of health improvement and protecting environments. AUT adds resources and the skills of faculty and students to build an academic / community partnerships. Success will be measured by student capacity-building outcomes, improvements in community health status and measures of empowerment, and community-perceived gains in sustainability.

\section{Method}

Healthy Cities South Auckland, starting in 2019, involved AUT South faculty and students, many of whom are from Māori and Pacific communities, working collaboratively. A distinctive feature of the initiative is that it involves a series of individually-funded and codesigned projects, focused on youth leadership and principles of sustainability, that focus on people, communities and the environment.

The initiative's first project, starting in 2019 and ongoing, involves research into the food environment of South Auckland and considers its possible implications in the relatively poor health of the community as well as its lack of sustainability. This project drew on the experiences of earlier research conducted in Suva, Fiji, which found that Pacific food environments are heavily reliant on imported processed foods (much of it with limited nutritional value); whilst there is limited support for local enterprise, agriculture and marketing (Conn et al., 2020). To date, the approach to much needed improvements in nutrition has focused on individual behaviour change (Willett et al., 2019), which places responsibility on individuals and families to change their eating patterns. This has not taken into consideration the effects of food environments on the health of people and planet, and has neglected the responsibility of society as a whole in assuring healthy sustainable food systems. Thus, in Aotearoa New Zealand 
and the Pacific Islandswhere, traditionally, communities primarily ate locally grown crops and seafood, imported or highly processed foods have replaced these, with detrimental results for people's health and for Pacific environments.

Two key activities relating to the work on food environments were: a symposium at AUT South Campus held in October 2018, titled 'Our people, our food, our planet', drawing from the Fiji study, which highlighted local community health concerns and solutions, and a student-faculty review conducted in 2019 on the current typology of food environments, exploring metaphors associated with harmful and beneficial environments. This review postulated that there was a need to focus less on an individual's ability to resist the unhealthy 'food swamp' nature of their environment, and instead foster 'food havens', that is, healthy environments that would foster better eating practices (Cammock et al., 2020; Tonumaipe'a, et al., 2020). Also, the review suggested that such metaphors and typologies, important as symbols of change, may benefit from the use of indigenous knowledge and philosophies, such as Māori Kaitiakitanga (guardianship of the natural order) and Pacific Va (healthy spaces).

A subsequent project, beginning in 2019, involved public health higher education codesign by and for Māori and Pacific undergraduate students at AUT. Using a series of codesign focus groups, the project embraced emerging technologies and opportunities to maximize youth employability in a rapidly changing society. It offered a platform for the re-conceptualization of education, one that is more student-driven and personalised (Kersey et al., 2018). This is manifested in a form of education that fosters collaboration between teachers, learners and industry, alongside digital fluency, where students use diverse forms of expression and work on real-world projects. In the context of public health, student and faculty codesigners placed a greater emphasis on multimedia approaches, creativity, and problemsolving building on themes identified as important by youth.

\section{Discussion}

From healthy cities to sustainable healthy cities

In recent years, the notion of the healthy city, with an emphasis on the health of urban communities, has evolved in response to the increasingly urgent drive towards sustainable environments. Various movements encompass this shift. One Planet Cities, One Health, Planetary Health, 
Urban Health, Ecohealth, to mention a few (Walton, 2019) - all have a dimension of achieving healthier communities, while at the same time advocating for more sustainable living. In further exploration of these ideas, Walton (2019) described One Health as a multidisciplinary framework that ensured different disciplines collaborated to work towards the optimal health of the planet. That is, the health of people, animals, and the environment. Also, Walton - presenting the term Ecohealth- defined it as a systems-based approach for promoting health and wellbeing with a focus on social and ecological interactions. In Whitmee et al. (2015), and a sequel publication by Horton and Lo (2015, p. 1921), the simple definition given to planetary health is 'the health of human civilisation and the state of the natural systems on which it depends'. This moves the agenda on more explicitly, acknowledging the existential challenge of climate change, to that expressed more subtly by WHO (1998) with Healthy Cities.

Similarly, while traditional approaches to food and nutrition in Aotearoa New Zealand have focused on individual and family lifestyles, Healthy Cities South Auckland focuses more overtly on sustainability and environment such as that of the food environment. This heralds a shift from health education paradigms to one that creates opportunities for innovation, enterprise and prosumerism, with active participation by communities in a process of change to urban food environments through digital tools, local enterprise, and other community action mechanisms. Prosumerism is defined as the consumer taking part in the design process of the services or products consumed (Santomier \& Hogan, 2013; Toffler \& Alvin, 1980). It can also be conceptualised as blending the line between producer and consumer (Paltrinieri \& Esposti, 2013). This approach aims to take into consideration the physical environment and the health effects of the food industry and, pertinent to the South Auckland context, it aims to address the inequities evident in a food system where 'food swamps' in urban areas are more common than 'food havens' (Tonumaipe'a, et al., 2020).

Thus, in general, Healthy Cities South Auckland aims to learn from and contribute to new movements in urban health and sustainability, and contribute by capturing emerging experiences and sharing them locally and globally through sustainable food systems research (Cammock et al., 2020; Tonumaipe'a, et al., 2020).

\section{Indigenous guardianship and urban health}

Alongside a growing appreciation of the global shift in thinking from healthy cities to sustainable cities is the growing realisation, through the South 
Auckland study of food swamps, that Aotearoa New Zealand offers a unique model of indigenous guardianship to strengthen health and wellbeing efforts. In 2019, the town of Rotorua, North Island, hosted the world conference titled 'Waiora: Promoting Planetary Health and Sustainable Development for All' (for the International Union for Health Promotion and Education/IUHPE 2019). It was clear from this event and the following Waiora (health for all) Statement that New Zealand offered a role model for public health indigenous stewardship. This offers us a special advantage in designing and implementing a healthy and sustainable cities agenda in New Zealand; one that may have relevance for other cities.

New Zealand's bicultural constitution, based on the Treaty of Waitangi signed in 1840, provides an ideal context for acknowledgement and celebration of indigenous guardianship: Kaitiakitanga, a deeply embedded value of Māori as guardians of the land (Walker et al., 2019). Previously associated with land and marine rights, as society becomes more urbanised we see Kaitiakitanga (guardianship of the natural order), and Pacific Va (healthy spaces), and the stewardship traditions of diverse communities in South Auckland offering special opportunities for guardianship of urban spaces. This seems particularly apt in a post-COVID world, as it may be that lack of guardianship of the planet has contributed to our vulnerability to pandemics.

\section{Youth social movements in the digital age}

A key focus on the involvement and development of Māori and Pacific youth from South Auckland is central to Healthy Cities South Auckland. The initiative responds to changing notions of youth social action and engagement, with youth leadership at its heart. These notions resonate with global shifts such as the school strike climate change movement which began in 2019, which for the first time positioned school-age young people as key leaders and stakeholders in decisions about climate change. Decisions about the future must include youth, not only as participants, but also as leaders in addressing disease outbreaks, chronic disease and health inequities, in a way which takes into consideration the links between people and natural environment.

\section{Conclusion}

Whilst the initiative is still in an early phase, we believe that we have already gained some important understandings. In particular, it has further demonstrated the urgent need to be more proactive in our emphasis on 
changing environments. For example, in fostering change to food environments in South Auckland. The codesign, participatory, and evolving nature of the projects have been enthusiastically received by participating Māori and Pacific youth, industry, faculty and other stakeholders. They have welcomed opportunities to influence change for a very different future for cities, for business and society, and for higher education. Youth participating were keen to benefit from contextual advantages such as cultural diversity and traditions, as well as technology in health. Our overarching goal is to continue to support small and large scale projects which adopt the paradigms described here, are sufficiently responsive to being youth-led and shaped, and whichaim to identify ways for youth to influence and drive transformative change. In 2021, plans include codesign research with youth food entrepeneurs (enterprises include food trucks and food delivery services) in South Auckland to promote sustainable and healthy environments; and a student initiative involving project design of food havens in their local neighbourhoods.

We believe that the active participation of youth in a codesigned project such as that of public health education transformation demonstrates that a university can provide a solid foundation for a future-oriented urban health academic-community-industry collaboration. The model of Healthy Cities South Auckland may be transferable to communities in other countries. Short-term success will be measured by scholarly productivity, including publications and presentations that include faculty, students and community contributions. Longer-term success will be measured by Māori and Pacific student gains, and South Auckland community health and environment gains for the longterm

\section{References}

Auckland Council. (2018). Auckland Plan 2050 evidence report: Demographics. https://bit.ly/312GSzN

Auckland Council. (2020). About Auckland. https://bit.ly/351xVBa

Auckland University of Technology. (2020). Facts and figures about AUT. https://www.aut.ac.nz/about/auts-leadership/fact-and-figuresabout-aut

Cammock, R., Tonumaipe'a, D., Conn, C., Sa'uLilo, L., Tautolo, E., Nayar, S. (2020). From individual behaviour strategies to sustainable food 
systems: Countering the obesity and non-communicable diseases epidemic in New Zealand. Health Policy, doi: https://doi.org/10.1016/j.healthpol.2020.12.001

C40 Cities. (2020). C40 Cities. https://www.c40.org/

Conn, C., Cammock, R., Sa'u Lilo, L., \& Nayar, S. (2020). Fijian youth entrepreneurs: championing health through sustainable food systems. Health Promotion International. https://doi.org/10.1093/heapro/daaa047

Hobbs, M., Ahuriri-Driscoll, A., Marek, L., Campbell, M., Tomintz, M., \& Kingham, S. (2019). Reducing health inequity for Māori people in New Zealand. The Lancet, 394(10209), 1613-1614. doi:10.1016/s01406736(19)30044-3

Horton, R., \& Lo, S. (2015). Planetary health: a new science for exceptional action. The Lancet, 386(10007), 1921-1922. http://dx.doi.org/10.1016/S0140-6736(15)61038-8

Kersey, K., Lees, A., Conn, C., Cochrane, T., Narayan, V., \& Williams, M. (2018). "Context matters": The challenges and opportunities of designing tertiary public and environmental health education in South Auckland. Pacific Health, 1(1), 1-12. https://doi.org/10.24135/pacifichealth.v1i1.8

Ministry of Health NZ. (2019a). Auckland DHB. https://www.health.govt.nz/new-zealand-health-system/mydhb/auckland-dhb

Ministry of Health NZ. (2019b). Population of Counties Manukau DHB. https://bit.ly/2I6mkaX

New Zealand Now. (2020). Discover the Auckland Region. https://www.newzealandnow.govt.nz/regions-nz/auckland

NZ Labour Party. (2020, April 17). COVID-19 economic response. https://www.labour.org.nz/c19-econ

Paltrinieri, R., \& Esposti, P. D. (2013). Processes of Inclusion and Exclusion in the Sphere of Prosumerism. Future Internet, 5(1), 21-33. https://www.mdpi.com/1999-5903/5/1/21

Santomier, J., \& Hogan, P. (2013). Social media and prosumerism: implications for sport marketing research. In Handbook of research on sport and business. Edward Elgar Publishing. doi: $\underline{10.4337 / 9781781005866 .}$.

Sheridan, N. F., Kenealy, T. W., Connolly, M. J., Mahony, F., Barber, P. A., Boyd, M. A., Carswell, P., Clinton, J., Devlin, G., Doughty, R., Dyall, L., Kerse, N., Kolbe, J., Lawrenson, R., \& Moffitt, A. (2011). Health equity in the New Zealand health care system: a national survey. 
International Journal for Equity in Health, 10(1), 45. doi:10.1186/1475-9276-10-45

Stats NZ. (2020a). 2018 Census place summaries: Auckland region. https://www.stats.govt.nz/tools/2018-census-placesummaries/auckland-region

Stats NZ. (2020b). Area unit population projections, characteristics, 2013(base)-2043 update: Auckland. http://nzdotstat.stats.govt.nz/wbos/Index.aspx?DataSetCode=TABL ECODE7549

Stats NZ. (2020c). Household income and housing-cost statistics: Year ended June 2019. In Information releases (Ed.). Online: Stats NZ. https://bit.ly/3mXYA8c

Stats NZ. (2020d). 2018 Census totals by topic - national highlights (updated). https://www.stats.govt.nz/information-releases/2018census-totals-by-topic-national-highlights-updated

Stats NZ. (2020e). 2018 Census population and dwelling counts. https://bit.ly/3etFmUI

Taylor, M., \& Laville, S. (2020). City leaders aim to shape green recovery from coronavirus crisis. The Guardian. https://bit.ly/3etkQ6T

Toffler, A., \& Alvin, T. (1980). The third wave. Vol. 484: Bantam books New York.

https://pdfs.semanticscholar.org/e6fc/9faef8733f11599be3b5e2fbd 60089b118a5.pdf

Tonumaipe'a, D., Cammock, R., \& Conn, C. (2020). Food Havens not Swamps: a strengths-based approach to sustainable food environments [Manuscript submitted for publication]. Centre for Child Youth Research (CCYHR), Auckland University of Technology (AUT). https://doi.org/10.1093/heapro/daab021

Walker, E. T., Wehi, P. M., Nelson, N. J., Beggs, J. R., \& Whaanga, H. (2019). Kaitiakitanga, place and the urban restoration agenda. New Zealand Journal of Ecology, 43(3), 1-8. doi:10.2307/26841824

Walton, M. (2019). One Planet, One Health. Sydney University Press. https://doi.org/10.2307/j.ctvggx2kn

Whitmee, S., Haines, A., Beyrer, C., Boltz, F., Capon, A. G., de Souza Dias, B. F., Ezeh, A., Frumkin, H., Gong, P., Head, P., Horton, R., Mace, G. M., Marten, R., Myers, S. S., Nishtar, S., Osofsky, S. A., Pattanayak, S. K., Pongsiri, M. J., Romanelli, C., ... Yach, D. (2015). Safeguarding human health in the Anthropocene epoch: report of The Rockefeller Foundation Commission on Planetary Health. The Lancet, 386(10007), 1973-2028. doi:10.1016/S0140-6736(15)60901-1 
Willett, W., Rockström, J., Loken, B., Springmann, M., Lang, T., Vermeulen, S., Garnett, T., Tilman, D., DeClerck, F., Wood, A., Jonell, M., Clark, M., Gordon, L. J., Fanzo, J., Hawkes, C., Zurayk, R., Rivera, J. A., De Vries, W., Majele Sibanda, L., ... Murray, C. J. L. (2019). Food in the Anthropocene: the EAT Commission on healthy diets from sustainable food systems. The Lancet, 393(10170), 447-492. doi:10.1016/S01406736(18)31788-4

World Health Organization. (1998). Terminology for the European Conference on Health, Society and Alcohol: A glossary with equivalents in French, German and Russian. WHO (EURO). https://www.who.int/healthpromotion/about/HPR\%20Glossary\%20 1998.pdf?ua $=1$

World Population Review. (2020). New Zealand population: Demographics, maps, graphs. https://worldpopulationreview.com/countries/newzealand-population/ 